\title{
Prognostic Factors for Long Term Results of the Treatment of Patients with Malignant Submandibular Gland Tumors
}

\author{
Vincent L. M. Vander Poorten, M.D., M.Sc. ${ }^{1}$ \\ Alfonsus J. M. Balm, M.D., Ph.o. ${ }^{1}$ \\ Frans J. M. Hilgers, M.D., Ph.D. ${ }^{1}$ \\ I. Bing Tan, M.D., Ph.D. ${ }^{1}$ \\ Barbara M. Loftus-Coll, M.D. ${ }^{2}$ \\ Ronald B. Keus, M.D. ${ }^{3}$ \\ Augustinus A. M. Hart, m.sc. ${ }^{3}$ \begin{abstract}
Surgery, Pathology, and Radiotherapy, The Netherlands Cancer Institute (Antoni van Leeuwenhoek Ziekenhuis), Amsterdam, the Netherlands.

${ }^{2}$ Department of Pathology, The Netherlands Cancer Institute (Antoni van Leeuwenhoek Ziekenhuis), Amsterdam, the Netherlands.

${ }^{3}$ Department of Radiotherapy, The Netherlands Cancer Institute (Antoni van Leeuwenhoek Ziekenhuis), Amsterdam, the Netherlands.
\end{abstract} \\ ${ }^{1}$ Departments of Otolaryngology/Head and Neck
}

Presented at the meeting of the Royal Belgian Society for Ear Nose Throat Head and Neck Surgery, March 7, 1998, Brussels, Belgium.

Supported by a grant from the Horlait Medical Foundation, Brussels, Belgium.

Vincent L. M. Vander Poorten's current address is Department of Otorhinolaryngology, Head and Neck Surgery, University Hospital St. Raphael, Leuven, Belgium.

Address for reprints: A. J. M. Balm, M.D., Ph.D., Department of Otolaryngology/Head and Neck Surgery, the Netherlands Cancer Institute (Antoni van Leeuwenhoek Ziekenhuis), Plesmanlaan 121, 1066 CX Amsterdam, the Netherlands.

Received August 3, 1998; revision received November 30, 1998; accepted December 23, 1998.
BACKGROUND. Concerning malignant submandibular gland tumors, a rare disease entity, there are few recent reports of long term treatment results and of prognostic factors modifying these results.

METHODS. The clinical data of 43 patients with malignant submandibular gland tumors who were treated at the Netherlands Cancer Institute between 1973 and 1994 were reviewed to evaluate treatment results and to control described prognostic factors. The median follow-up for patients alive at the end of follow-up was 143 months. Only univariate analyses were performed.

RESULTS. The crude 5- and 10-year survival rates were 50\% and 36\%, respectively; the 5- and 10-year disease specific survival (DSS) rates were $61 \%$ and $51 \%$, respectively; and the 5- and 10-year recurrence free percentages were $57 \%$ and $52 \%$, respectively. Factors predicting crude survival were age at diagnosis $(P=0.0006)$, International Union Against Cancer/American Joint Committee on Cancer (UICC/ AJCC) TNM classification and its regrouping into tumor stage $(P=0.001)$, and clinical skin invasion $(P=0.005)$. In surgically treated patients, soft tissue invasion $(P=0.005)$, metastatic lymph nodes $(P=0.006)$, and perineural growth $(P=0.01)$ were prognostic for survival. Factors predicting DSS were the UICC/AJCC TNM classification and regrouping into tumor stage $(P=0.002)$. In surgical patients, perineural growth $(P=0.0008)$ conferred a lower DSS. Factors predicting tumor recurrence were the UICC/AJCC TNM classification and its regrouping into tumor stage $(P=0.009)$. In surgical patients, perineural growth $(P=0.003)$ predicts tumor recurrence.

CONCLUSIONS. Of patients with submandibular gland carcinoma treated according to a stable treatment protocol in a European tertiary referral center, $52 \%$ were tumor free 10 years later. Patients exhibiting the described adverse prognostic factors are likely to benefit from added radiotherapy. Cancer 1999;85:2255-64. (C) 1999 American Cancer Society.

KEYWORDS: salivary gland neoplasms, submandibular gland carcinoma, treatment results, prognostic factors.

Q alivary gland malignancies in general are rare tumors, and their - image is complicated further by a remarkable histologic diversity $^{1,2}$ specific to salivary gland tissue. Within these malignancies, tumors arising in the submandibular gland form a well-defined clinical entity with a well-defined treatment technique.

To diagnose one new case in the male Dutch population, one million men at risk must be followed for 1 year: the age-adjusted, world standardized incidence ratio per $10^{6}$ person years in the Netherlands is 1.0 for men and 0.4 for women. ${ }^{3}$ It is evident that clinical experiences with this type of disease are scarce. The low 
TABLE 1

Variables in the Analysis

\begin{tabular}{|c|c|}
\hline Variable & Levels \\
\hline Age (yrs) & $<40,40-70,>70$ \\
\hline Gender & Male vs. female \\
\hline Duration complaints (weeks) & $<6,6-24,>24$ \\
\hline Pain at presentation & Pain or numbness: yes vs. no/not reported \\
\hline T classification & $\mathrm{Tl}-\mathrm{T} 4$ \\
\hline N classification ${ }^{\mathrm{a}}$ & N0 vs. any lymph nodes \\
\hline M classification ${ }^{\mathrm{a}}$ & M0 vs. M1 \\
\hline Stage $^{\mathrm{a}}$ & I-IV \\
\hline Skin invasion & Yes vs. no/not reported (untreated patients) \\
\hline Local extension ${ }^{\mathrm{a}}$ & Clinical evidence of skin, soft tissue, bone, or nerve invasion vs. no such evidence \\
\hline High low grade ${ }^{\mathrm{b}}$ & $\begin{array}{l}\text { High grade (high grade mucoepidermoid carcinoma, adenocarcinoma, undifferentiated carcinoma, squamous cell carcinoma, } \\
\text { malignant mixed tumor, adenoid cystic carcinoma) vs. low grade malignancy group (acinic cell carcinoma, low grade } \\
\text { mucoepidermoid carcinoma) }\end{array}$ \\
\hline Soft tissue extension ${ }^{\mathrm{c}}$ & $\begin{array}{l}\text { Histologic evidence of extraglandular extension (skin, bone, nervous, or vascular structure invasion; positive section margins } \\
\text { or extranodal spread in the neck dissection specimen) vs. no such evidence }\end{array}$ \\
\hline Metastatic lymph nodes ${ }^{\mathrm{d}}$ & Histologic evidence of metastatic lymph nodes in the neck dissection specimen vs. no such evidence \\
\hline Perineural growth & Described vs. not described in the pathology report \\
\hline Surgical margins ${ }^{\mathrm{c}}$ & Positive vs. "close and negative margins" \\
\hline Vascular invasion ${ }^{\mathrm{c}}$ & Described vs. not described in the pathology report \\
\hline Tumor spill ${ }^{\mathrm{c}}$ & Yes vs. no or not reported in the operative report \\
\hline Previous treatment ${ }^{\mathrm{c}}$ & Patients without vs. with incisional or excisional biopsy at presentation \\
\hline Treatment type & Surgery, surgery followed by RT, RT \\
\hline Interval surgery/RT $\mathrm{R}^{\mathrm{e}}$ (weeks) & $<5$ vs. $>5$ \\
\hline \multicolumn{2}{|c|}{ RT: radiotherapy. } \\
\hline \multicolumn{2}{|c|}{${ }^{a}$ International Union Against Cancer/American Joint Committee on Cancer TNM classification. ${ }^{8,9}$} \\
\hline \multicolumn{2}{|c|}{$\begin{array}{l}\text { b World Health Organization } 1972 \text { and Million et al. }{ }^{10} \text { Spiro and colleagues }{ }^{11,12} \text { use the same reference level (low grade mucoepidermoid and acinic cell carcinoma). } \\
{ }^{\mathrm{c}} \text { Onlv evaluated for surgical patients. }\end{array}$} \\
\hline \multicolumn{2}{|c|}{ c Only evaluated for surgical patients. } \\
\hline \multicolumn{2}{|c|}{ d Only evaluated for N0 patients who had surgery (only one N1 patient had a neck dissection, the rest of $\mathrm{N}$ positive patients did not). } \\
\hline \multicolumn{2}{|c|}{ e Only evaluated for patients who had surgery followed by RT. } \\
\hline
\end{tabular}

incidence makes it difficult to evaluate the natural history, prognostic factors, and different treatment modalities in a prospective manner. Therefore, to date, this information relies on retrospective analyses. The early authors remained purely descriptive; 4,5 more recently, one tried to identify prognostic factors through statistical analysis, looking at crude survival, ${ }^{6}$ disease specific survival, or tumor recurrence. $^{7}$

Our long-standing experience with this disease and a consistent treatment policy over the years, including a long follow-up (median, 143 months for patients alive at the end of follow-up), form a good starting point for a thorough statistical evaluation looking at different important outcomes in oncology: crude survival, disease specific survival, and tumor free interval. Therefore, our group of 43 patients who were treated between 1973 and 1994 was studied for treatment results and the major prognostic indicators before and after treatment, and the findings were compared with those in the literature. $^{6,7}$

\section{PATIENTS AND METHODS}

From January 1, 1973 to January 1, 1995, 243 patients with the primary histologic diagnosis of a malignant salivary gland tumor presented at our institute. Fortythree of them (16\%) had a submandibular gland carcinoma. Of these, 36 patients (84\%) received their complete, definitive protocollary treatment in our institute (surgery with or without preceding surgery elsewhere, with or without postoperative radiotherapy), 6 patients were referred to our Department of Radiotherapy after adequate surgery in the referring hospital, and 1 patient was not treated at all. The study population consisted of 22 women (51\%) and 21 men $(49 \%)$. The median age at diagnosis was 59 years (range, 20-84). According to our institutional policy, informed consent for retrospective studies was not requested.

All clinical information was extracted from the patient files. Factors investigated for prognostic value were patient characteristics, clinical and histologic tumor characteristics, and treatment characteristics (Table 1). 
TABLE 2

TNM Classification and Stage Grouping ${ }^{a}$

\begin{tabular}{|c|c|c|c|c|c|c|c|}
\hline \multirow[b]{2}{*}{ TNM (\%) } & \multicolumn{2}{|c|}{ N0 (81\%) } & \multicolumn{2}{|c|}{ N1 (7\%) } & \multicolumn{2}{|c|}{ N2-N3 (10\%) } & \multirow{2}{*}{$\begin{array}{l}N \text { missing } \\
(2 \%)\end{array}$} \\
\hline & No. & Stage & No. & Stage & No. & Stage & \\
\hline T1 (18.5) & 6 & I & 1 & III & 0 & IV & 1 \\
\hline T2 (28) & $12(1)^{b}$ & II & 0 & III & 0 & IV & 0 \\
\hline Т3 (18.5) & 7 & III & 0 & III & $1(1)$ & IV & 0 \\
\hline T4 (21) & 4 & IV & 2 & IV & $3(2)$ & IV & 0 \\
\hline T missing (14) & 6 & - & 0 & - & 0 & - & 0 \\
\hline
\end{tabular}

${ }^{a}$ International Union Against Cancer TNM classification. ${ }^{8}$

${ }^{\mathrm{b}}$ The numbers of M1 status patients in this T-N combination are indicated in parentheses. The one patient with the T2 N0 M1 has Stage IV disease.

TABLE 3

Distribution of Histologic Types

\begin{tabular}{llll}
\hline WHO 1972 Type & $\begin{array}{l}\text { Original } \\
\text { Diagnosis }^{\mathbf{a}}\end{array}$ & $\begin{array}{l}\text { Revision } \\
\text { WHO 1972 }\end{array}$ & $\begin{array}{l}\text { Revision } \\
\text { WHO 1991 }\end{array}$ \\
\hline Acinic cell & 3 & 4 & 4 \\
Mucoepidermoid & $2^{\mathrm{c}}$ & 0 & 0 \\
Adenoid cystic & 18 & 16 & 16 \\
Adenocarcinoma & 8 & 6 & 3 \\
Malignant mixed & 4 & 2 & 2 \\
Squamous cell & 2 & 2 & 2 \\
Undifferentiated & 4 & 2 & 2 \\
Others & 2 & & $3^{\mathrm{d}}$ \\
Total & 43 & 32 & 32 \\
\hline
\end{tabular}

WHO: World Health Organization.

${ }^{a}$ Used for inclusion based on data form surgical resection specimen, incisional biopsy, or aspiration cytology.

${ }^{\mathrm{b}}$ Based only on slides of surgical resection specimens. The diagnosis for 11 patients could not be revised (based on cytology [ $=5]$, lost slides in regional hospitals [ $n=2]$, or lost slides in our own archives $[\mathrm{n}=4]$ )

${ }^{\mathrm{c}}$ Mucoepidermoid carcinomas in our series were low grade mucoepidermoid carcinomas.

d "Others" in WHO 1991 classification are one polymorphous low grade adenocarcinoma, one salivary duct carcinoma, and one basal cell adenocarcinoma, classified as adenocarcinoma according to the WHO 1972 classification.

Clinical TNM classification was according to the 1992 International Union Against Cancer (UICC) guidelines $^{8}$ (Table 2). Histology of the resection specimen was reviewed and reclassified according to the World Health Organization (WHO) classifications of 1972 and $1991^{1,2}$ (Table 3). Levels of the WHO classification were reduced to a dichotomy of clinically high grade malignant versus clinically low grade malignant tumors, as shown in Table 1. For surgical patients, information on histopathologic tumor characteristics was abstracted from the original pathology report.

Recurrences were noted as the first site of failure. Patients with residual tumor at the end of therapy were attributed an artificial recurrence free period of 0.1 month.

All patients presented with submandibular swell- ing, existing for a median duration of 13 months (range, 1-330 months). The swelling was painless in 31 patients $(72 \%)$, whereas 12 patients $(28 \%)$ had experienced local pain. Skin invasion was difficult to evaluate in patients who underwent previous incisional biopsy or had an inadequate resection (excisional biopsy). Before any treatment, visible skin invasion was present in only three patients. In one of them, a paresis of the marginal mandibular branch of the facial nerve existed. This symptom also was present in two patients with swelling without skin invasion. In one patient, there was fixation to the mandible. Seven patients $(17 \%)$ presented with clinically palpable lymphadenopathy. Three of them also had distant metastases. One patient had distant metastases without regional lymph node involvement. TNM classification $^{8,9}$ could be performed in 36 of the 43 patients, resulting in 6 patients with Stage I disease, 11 with Stage II disease, 8 with Stage III disease, and 11 with Stage IV disease (Table 2). Diagnosis was made by means of histology of resection specimen $(n=35)$ for surgical patients and incisional biopsy $(n=3)$ or aspiration cytology $(n=5)$ for nonsurgical patients (Table 3).

The majority of patients $(n=29 ; 67 \%)$ received standard therapy, consisting of surgery followed by radiotherapy. Surgery alone was performed in 6 patients $(14 \%)$. Of the 35 surgical patients, only 7 were without any previous treatment; the remaining 28 had undergone an incisional biopsy $(\mathrm{n}=15)$ or an inadequate resection elsewhere $(n=13)$.

The standard surgical procedure consisted of a supraomohyoid neck dissection in 24 patients, an extended supraomohyoid neck dissection with excision of the floor of the mouth and inferior mandibular rim in 2 patients, a radical neck dissection in 8 patients, and a modified radical neck dissection in 1 patient. In 7 of 32 N0 patients who underwent neck dissection, one or more metastatic lymph nodes were recovered 
(occult rate, 22\%). Only one patient with an N1 classification had a neck dissection confirming metastatic disease; none of the other lymph node positive patients was treated surgically.

Postoperative radiotherapy (wedged-pair technique, $48 \%$; midline dosage, $21 \%$; isodensity dosage, $31 \%$; isolated photon therapy, $69 \%$; combination of photons and electrons, $28 \%$; isolated electron therapy, $3 \%$ ) was given to a local median dose of 6000 centigrays (cGy) during a median period of 43 days and, in $34 \%$ of patients, associated with a regional median dose of 5000 cGy during a median period of 37 days. Both local radiotherapy and regional radiotherapy were given in median fractions of 200cGy. The median interval between surgery and the onset of the postoperative radiotherapy was 6 weeks.

Isolated radiotherapy was used for six patients who were judged inoperable (two of them received neutron irradiation to a dose of $1600 \mathrm{cGy}$ in fractions of 80 cGy during a period of 30 days). One patient received palliative chemotherapy, and one patient received no treatment at all.

\section{Follow-Up}

Follow-up was complete for 40 patients up to January 1,1995 , the closure date of the study. In 3 patients, the tumor status remained unknown. Two of these patients were alive without tumor recurrence at 85 months and 138 months of follow-up. The remaining patient had died due to an unknown cause with an unknown tumor status at 108 months of follow-up.

At the time of our analysis, 25 patients had died, and 18 patients were still continuing follow-up. Of these, 17 patients were alive without evidence of disease, and 1 was alive with recurrent disease. The median follow-up from the first day of diagnosis was 45 months (range, 1-274 months), whereas the median follow-up for patients alive at the end of their follow-up (excluding patients that died with a known tumor status) was 143 months or almost 12 years.

\section{Statistics}

The product-limit method as described by Kaplan and Meier $^{13}$ was used to calculate overall survival, DSS, and tumor free percentages. Presumed prognostic factors were evaluated univariately for significant differences in survival, DSS, and recurrence free intervals using the log-rank test, with the significance level set at $P<0.01$ because of the number of variables tested. Where appropriate for categorical data, a trend logrank test was performed. The end point in this analysis was the moment of death, the moment of disease specific death from the day of diagnosis, and the mo-

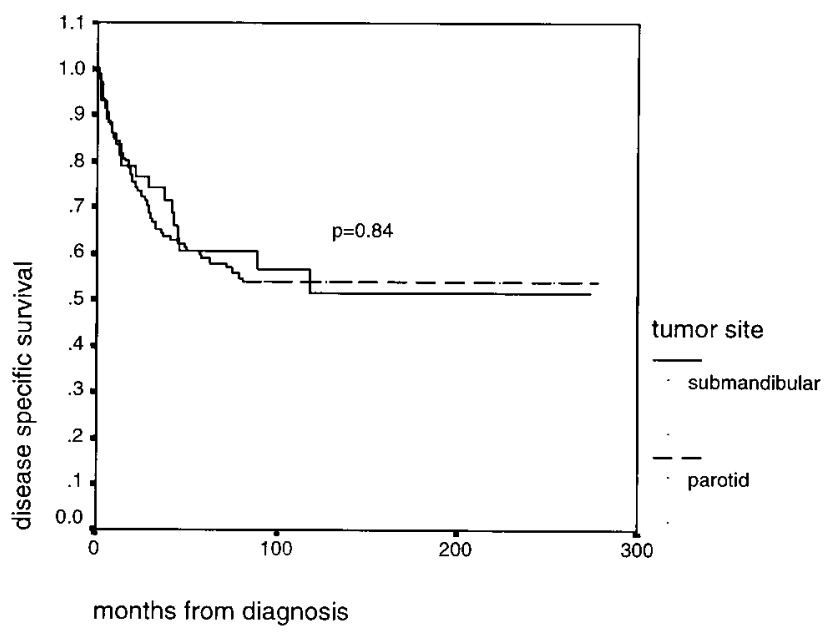

FIGURE 1. Kaplan-Meier disease specific survival curves by tumor site.

ment of tumor recurrence (local, regional, or distant) starting from the first day of definitive treatment.

\section{RESULTS}

Survival

The overall 5- and 10-year survival rates from the day of diagnosis were $50 \%$ (standard error [SE], 7\%) and $36 \%$ (SE, 8\%), and the 5- and 10-year DSS rates from the day of diagnosis were $61 \%$ (SE, $7 \%$ ) and $51 \%$ (SE, 9\%), respectively. In Figure 1, this DSS curve is compared with the DSS curve of 168 patients with primary malignant parotid tumors who were treated at our institute during the same period. ${ }^{14}$

\section{Recurrence-Residual Tumor}

Seven patients, including the four patients with an M1 classification at diagnosis, remained with residual tumor after treatment. Twelve patients who initially were free of tumor clinically at the end of therapy had recurrences after a median tumor free interval of 17 months. Local recurrence occurred in 3 patients, and regional recurrence without local recurrence occurred in 1 patient. Isolated distant metastasis occurred in 7 patients (16\%), whereas 1 patient presented with synchronous locoregional and distant metastasis. The 5and 10-year recurrence free percentages from the first day of therapy were $57 \%$ (SE, $8 \%$ ) and $52 \%$ (SE, $8 \%$ ), respectively.

Distant metastases occurred eventually in 16 patients, of whom 4 had distant metastases at presentation. The organs involved at the first diagnosis of distant metastasis were the lungs in 7 patients $(44 \%)$, the skeleton in 4 patients, the liver in 1 patient, and a combination of these in 4 patients. Eight of 18 patients with adenoid cystic carcinomas (44\%) developed dis- 
TABLE 4

Identified Prognostic Factors for Different Outcomes. $P$ Values According to the Log-Rank Test

\begin{tabular}{|c|c|c|c|}
\hline Prognostic Factors & Survival & $\begin{array}{l}\text { Disease } \\
\text { Specific } \\
\text { Survival }\end{array}$ & Recurrence \\
\hline \multicolumn{4}{|l|}{ Patient characteristics } \\
\hline Age & $0.0006^{\mathrm{a}}$ & 0.018 & 0.04 \\
\hline Gender & 0.93 & 0.67 & 0.97 \\
\hline Duration of complaints & 0.90 & 0.67 & 0.66 \\
\hline Pain at presentation & 0.95 & 0.75 & 0.26 \\
\hline \multicolumn{4}{|l|}{ Clinical tumor characteristics } \\
\hline $\mathrm{T}$ classification & 0.001 & 0.005 & 0.014 \\
\hline $\mathrm{N}$ classification & 0.003 & 0.0003 & 0.0001 \\
\hline M classification & 0.002 & 0.0002 & - \\
\hline Stage & 0.001 & 0.002 & 0.009 \\
\hline Skin invasion & 0.005 & 0.08 & 0.15 \\
\hline Local extension & 0.18 & 0.46 & 0.09 \\
\hline \multicolumn{4}{|c|}{$\begin{array}{l}\text { Histopathologic tumor characteristics } \\
\text { in surgical patients }\end{array}$} \\
\hline High/low grade & 0.02 & 0.07 & 0.05 \\
\hline Soft tissue invasion & 0.005 & 0.03 & 0.22 \\
\hline Metastatic lymph nodes & 0.006 & 0.026 & 0.08 \\
\hline Perineural growth & 0.01 & 0.0008 & 0.003 \\
\hline Surgical margins & 0.08 & 0.25 & 0.52 \\
\hline Vascular invasion & 0.19 & 0.06 & 0.10 \\
\hline \multicolumn{4}{|l|}{ Treatment characteristics } \\
\hline Tumor spill & 0.56 & 0.51 & 0.54 \\
\hline Previous treatment & 0.12 & 0.32 & 0.23 \\
\hline Treatment type & 0.0001 & 0.0003 & 0.0002 \\
\hline Interval surgery/radiotherapy & 0.14 & 0.43 & 0.92 \\
\hline
\end{tabular}

tant metastases, 1 of 3 acinic cell carcinomas, 1 of 2 mucoepidermoid carcinomas, 4 of 8 adenocarcinomas, and 1 of 4 carcinomas ex pleomorphic adenoma.

\section{Prognostic Factors for Survival}

An overview of the univariate analysis of prognostic factors for the different outcomes is given in Table 4 . Age was prognostic for survival: People $<40$ years of age have a $91 \% 5$-year survival rate compared with $50 \%$ for the age group $40-70$ years of age and a $16 \%$ 5 -year survival rate $>70$ years of age (trend log-rank test, $P=0.0006$; Fig. $2 \mathrm{a}$ ). Of three patients with clinically visible skin invasion, none survived for 5 years, whereas the other patients showed a $54 \%$ 5-year survival rate $(P=0.005)$.

Patients with Stage I disease had a 5-year survival rate of $83 \%$, patients with Stage II disease had an $81 \%$ 5 -year survival rate, patients with Stage III disease had a 25\% 5-year survival rate, and patients with Stage IV disease had an 18\% 5-year survival rate (trend log-rank test, $P=0.001$ ). These percentages show a clear dichotomy between patients with Stage I-II disease on one hand and patients with Stage III-IV disease on the other (log-rank test, $P=0.001$ ). In accordance with this dichotomy between stage groups differing in $\mathrm{N}$ classification, patients who were without clinically palpable regional metastases (5-year survival rate, $56 \%$ ) did better than patients who presented with regional metastases (5-year survival rate, 14\%; $P=$ 0.003). Classifying patients according to $\mathrm{T}$ status also resulted in prognostically different groups $(P=0.001)$ : patients with $\mathrm{T} 1$ tumors showed an $87.5 \%$ 5-year survival rate compared with only $22 \%$ for patients with T4 tumors.

Surgical patients who were diagnosed with a tumor displaying soft tissue invasion $(P=0.005$; Fig. $2 \mathrm{~b})$ or perineural growth $(\mathrm{P}=0.01$ ) had worse survivals. Of 32 surgically treated N0 patients, 7 had occult metastatic disease, as stated above, which influenced their survival negatively $(P=0.006)$. Thus, the group of N0 patients can be further subdivided with regard to prognosis based on the presence of histologically confirmed metastatic lymph node disease.

Patients who were treated with surgery alone (5year survival rate, $67 \%$ ) and patients who were treated with postoperative radiotherapy (5-year survival rate, $61 \%$ ) did better than patients who were treated with radiotherapy alone (no 5-year survivors; log-rank test, $P=0.0001)$. However, the difference was not significant $(P=0.51)$ in a pair-wise comparison of the first two groups.

\section{Prognostic Factors for DSS}

Analysis for DSS showed a similar prognostic effect of stage (trend log-rank test, $P=0.002$ ) with the same dichotomy between Stages I-II and Stages III-IV ( $P=$ 0.004; Fig. 3a). Logically, as explained above, clinically palpable lymph nodes conveyed a worse prognosis $(P=0.0003$; Fig. $3 \mathrm{~b})$.The prognostic effect of $\mathrm{T}$ status (trend log-rank test. $P=0.005$ ) also was reflected in the overall prognostic effect of stage grouping. Soft tissue invasion $(P=0.03)$ and its important component perineural growth $(P=0.0008)$ implicated a bad prognosis for surgical patients.

Patients who were treated with surgery and postoperative radiotherapy (5-year DSS, 74\%) and patients who were treated with surgery alone (5-year DSS, 67\%) did better than patients who were treated with radiotherapy alone (no 5-year DSS; log-rank test, $P=$ 0.0003; Fig. 3c). However, the difference between the first two groups in pair-wise comparison was not significant $(P=0.4)$. Previously untreated patients did better (5-year DSS, $86 \%$ ) than patients who had undergone an incisional biopsy or a previous inadequate resection (5-year DSS, 68\%) and better than patients who did not receive surgical treatment at all (none 


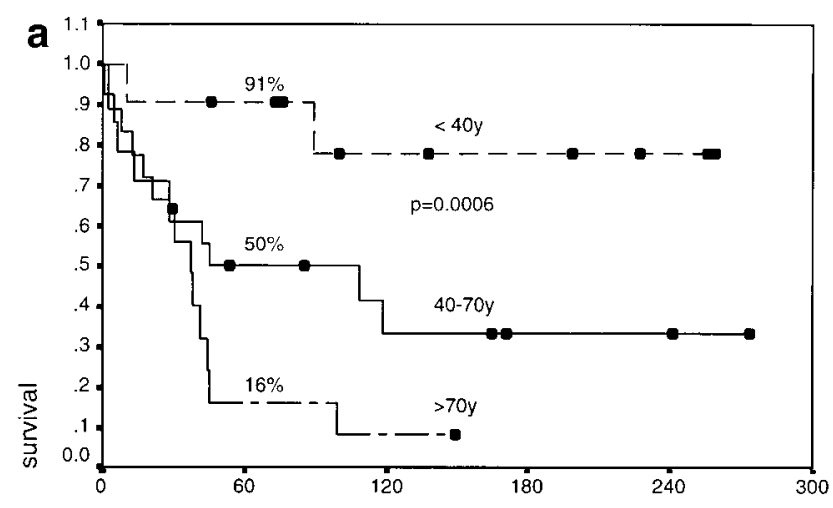

months from diagnosis

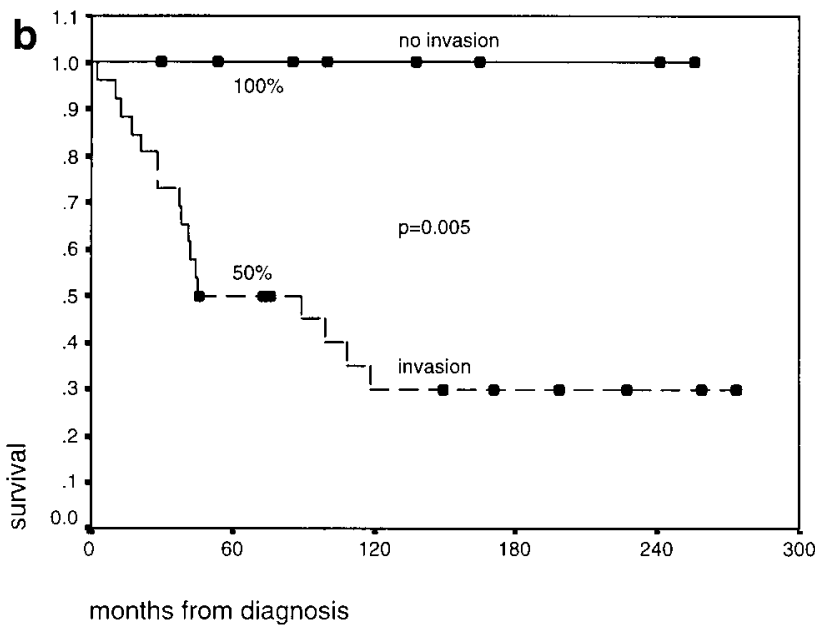

FIGURE 2. Kaplan-Meier overall survival curves by the prognostic factors age (in years) (a) and soft tissue extension (b). Bullets indicate censored patients.

survived for 5 years without tumor; $P=0.00001$ ). However, the difference in a pair-wise comparison of the first two groups was not significant $(P=0.32)$.

\section{Prognostic Factors for Recurrence}

Prognostic factors for recurrence free percentages were again stage (trend log-rank test, $P=0.009$ ), with the same dichotomy emerging between Stages I-II and Stages III-IV. Classifying patients according to N status $(P=0.0001)$ also resulted in prognostically different groups.

Surgical patients with tumors growing perineurally ( $P=0.003$; Fig. 4$)$ were significantly more subject to tumor recurrence. The presence of perineural growth resulted in a 5-year recurrence free percentage of $44 \%$ compared with $87 \%$ in the absence of it.

\section{DISCUSSION}

Similar to what has been described in other series $^{1,6,7,15,16}$ our patients presented in the sixth decade (mean age, 57 years; median age, 59 years) with an equal distribution between genders. ${ }^{7,15}$ This equal gender distribution was not expected, because the reported incidence density rates ${ }^{3}$ are 2.5 times higher in men. Referral bias is a possible explanation for this.

Symptoms were not alarming and consisted of a slowly growing, painless mass in the neck accompanied in exceptional cases by skin invasion or some form of nerve dysfunction. The median duration of symptoms was 13.5 months. The median duration of complaints may range from 3 years for low grade types to 6 months for high grade types. ${ }^{5,7}$ The extremes in our patients ranged from $<1$ month to $>27$ years. Almost one-third of the patients complained of pain, which is a sign of local extension. This striking com- plaint sometimes may be mentioned by half of the patients with submandibular gland malignancies. ${ }^{17}$

For the majority of histologic types, the frequency in our study by and large equals the percentages reported by others (Table 5). Differences should not be overemphasized in view of the small patient numbers and the possible referral biases. However, it is noteworthy that, in all cited series, adenoid cystic carcinoma comprises $40-45 \%$ of all cases. It was noted previously by Eneroth ${ }^{4}$ that adenoid cystic carcinoma is the most frequently encountered type of tumor by far. Only five patients could be assigned to the clinically low grade type malignancy group, defined as described in Table 1. In other series, this low grade malignant group also is a minority; therefore, in this respect, one could question the relevance of this dichotomy, which proved to be useful for parotid malignancies. ${ }^{10}$

The treatment of choice has shifted in the past decades from purely surgical (rather aggressive and extended resections ${ }^{5,15}$ ) to more functional and less extended surgery, according to the needs of the local situation, complemented with radiotherapy. ${ }^{6,7,11}$ The standard operation used to be oriented more toward including the submandibular gland in a radical neck dissection, often with en bloc excision of the floor of the mouth and lower rim of the mandible. ${ }^{5,15}$ The more recent tendency toward more preservative surgery has been demonstrated clearly by Spiro et al., ${ }^{11}$ who describe an increase in the use of a supraomohyoid neck dissection from none in the period 19391965 to $38 \%$ of the surgeries in the period 1966-1982. In our study period (1973-1994), 68\% of the operative procedures consisted of a standardized supraomohyoid neck dissection. This supraomohyoid neck dissec- 


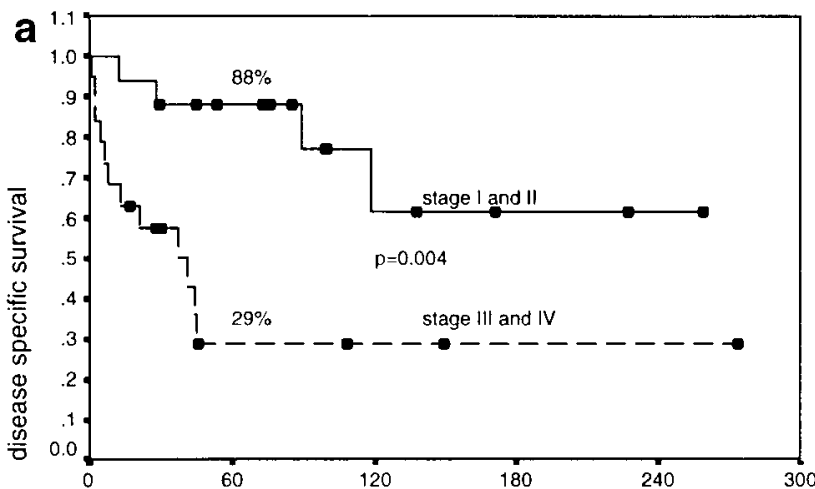

months from diagnosis

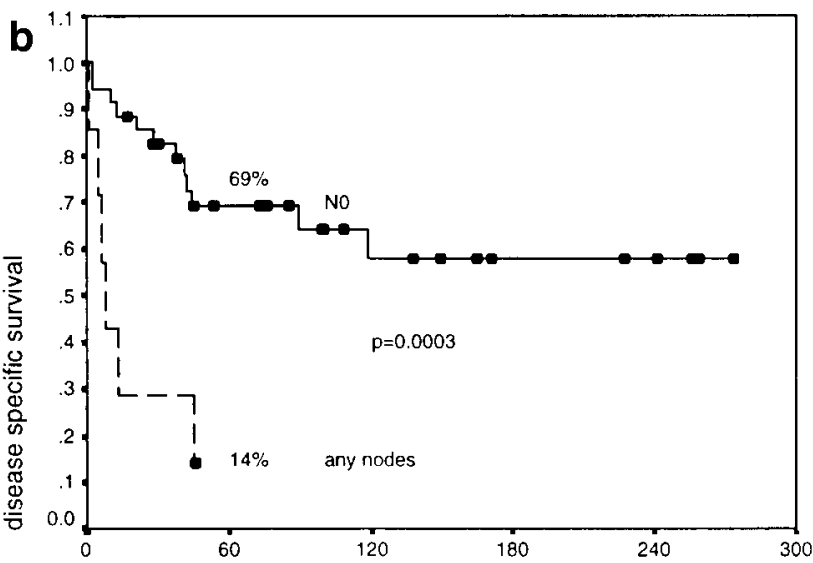

months from diagnosis

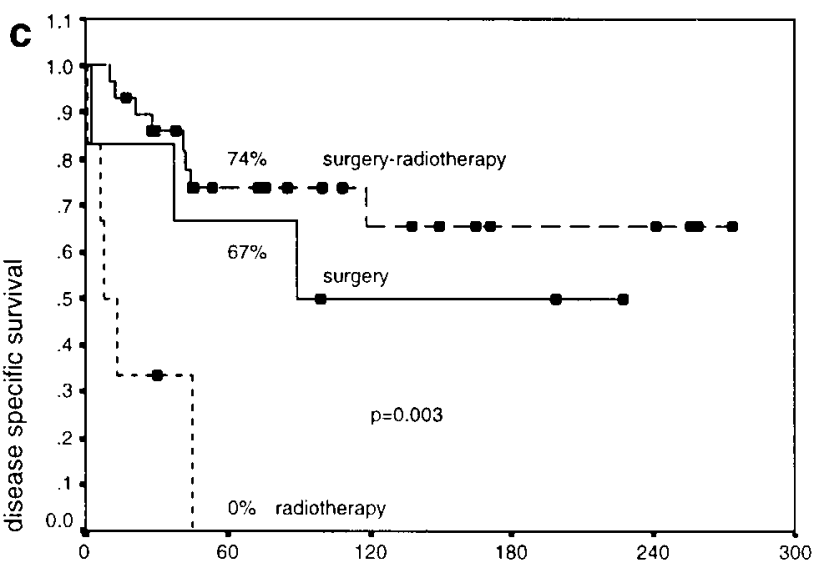

months from diagnosis

FIGURE 3. Kaplan-Meier disease specific survival curves by the prognostic factors stage (a), N classification (b), and treatment type (c). Bullets indicate censored patients.

tion accounted for $66 \%$ of operative procedures in the period $1973-1983$ and for $71 \%$ of the procedures between 1984 and 1994; therefore, its use was distributed evenly over the entire study period. Thus, the trend

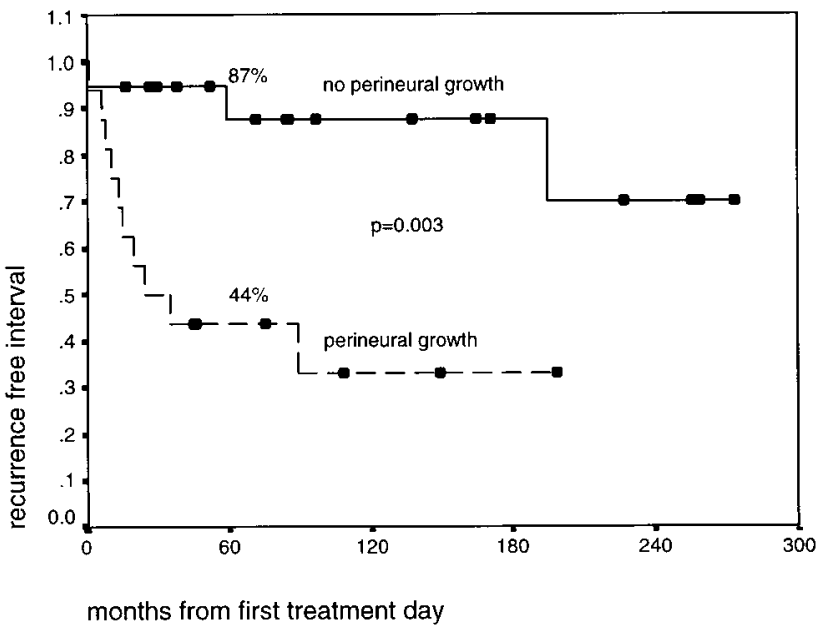

FIGURE 4. Kaplan-Meier recurrence free interval curves by perineural growth. Bullets indicate censored patients.

toward more conservative surgery is confirmed and seems to have increased even further. One should only extend the operation beyond the boundaries of the supraomohyoid dissection if the local extension of the disease makes this necessary. ${ }^{6}$ However, this is a relatively rare situation in previously untreated patients.

In the early 1970s, Conley et al. ${ }^{5}$ stated that there was no indication that irradiation should be given when an adequate operation has been performed; thus, only $12 \%$ of his patients were treated in a combined fashion. Even lower percentages of 3\% were published in those days. ${ }^{15}$ In contrast to this and in accordance to more recent recommendations, ${ }^{6,7,19}$ a majority of our patients $(67 \%)$ received combined treatment schedules as the standard treatment protocol. In the series at The Princess Margaret Hospital, ${ }^{7}$ $59 \%$ of patients were given postoperative irradiation; in that analysis, radiotherapy was found to improve locoregional control significantly. The role of postoperative radiotherapy, however, is questionable for the subgroup of patients with low grade malignancies. We do not believe that surgical removal of intraglandular tumors with safe margins, no soft tissue and perineural invasion should be followed by radiotherapy.

Overall survival rates in our series (5-year survival rate, $50 \%$; 10 -year survival rate, $36 \%$ ) are comparable to the results of a nationwide analysis showing a 5 -year survival rate of $52 \%{ }^{3}$ Crude survival rates in earlier series were lower ${ }^{15,19}$ or were in the same range. ${ }^{20}$ An exceptionally high figure was described by Weber et al., who reported a 5-year survival rate of $69 \%{ }^{6}$ in a population with a surprising majority of patients with T4B disease.

DSS in our series (5-year DSS, $61 \%$; 10 -year DSS, $51 \%$ ) is almost similar to the findings of Bisset and 
TABLE 5

Frequencies (\%) of Histologic Types According to Different Authors

\begin{tabular}{|c|c|c|c|c|c|c|}
\hline $\begin{array}{l}\text { WHO } 1972 \\
\text { Types }\end{array}$ & $\begin{array}{l}\text { Current Series }^{a} \\
(n=43)\end{array}$ & $\begin{array}{l}\text { Weber et al. } \\
(n=86)\end{array}$ & $\begin{array}{l}\text { Spiro et al. }{ }^{15} \\
(n=217)\end{array}$ & $\begin{array}{l}\text { Bisset and } \\
\text { Fitzpatrick }^{7} \\
(\mathrm{n}=91)\end{array}$ & $\begin{array}{l}\text { Andersen et al. }{ }^{18} \\
(\mathrm{n}=38)\end{array}$ & $\begin{array}{l}\text { Batzakis }^{16} \\
(\mathrm{n}=358)\end{array}$ \\
\hline Acinic cell & 11 & 1 & 1 & 4 & 0 & 1 \\
\hline Mucoepidermoid & 5 & 17 & 19 & 15 & 8 & 17 \\
\hline Adenoid cystic & 44 & 43 & 35 & 41 & 42 & 40 \\
\hline Adenocarcinoma & 19 & 10.5 & 12 & 15 & 16 & 10 \\
\hline Malignant mixed & 9 & 9 & 19 & 11 & 16 & 12 \\
\hline Squamous cell & 5 & 9 & 12 & 6 & 8 & 11 \\
\hline Undifferentiated & 7 & 5 & 2 & 8 & 8 & 9 \\
\hline Others & - & 5.5 & - & - & 1 & - \\
\hline
\end{tabular}

WHO: World Health Organization.

${ }^{a}$ Revised-reclassified diagnoses were completed with the best available histologic information available for nonrevisable pathological diagnoses.

Fitzpatrick $^{7}$ (5-year DSS, 60\%; 10-year DSS, 48\%). Again, earlier series show lower percentages. ${ }^{15,21}$

Unlike the paradigm that assumes that malignant submandibular gland tumors imply a worse prognosis than their parotid counterparts, ${ }^{4,15,16,21,22}$ we could not confirm this difference in our patients. In accordance with more recent findings in the literature $^{11,17,23,24,25}$ and as shown in Figure 1, overall survival for our patients is comparable to the overall survival of patients with malignant parotid tumors treated in our institution in the same treatment period (5-year survival rate, $46 \%$; 10-year survival rate, $39 \%$; $P=0.47) .{ }^{14}$ This indicates that site by itself may be less important than previously assumed.

Decreasing survival, as can be expected by the nature of age itself, parallels increasing age. Age at diagnosis (three categories: $<40$ years, $40-70$ years, and $>70$ years) is prognostic for survival after the diagnosis of a malignant submandibular gland tumor. The difference remains but, indeed, becomes less pronounced when DSS is taken into account (filtering out patients dying of other diseases), and it is even less pronounced when tumor control is including. Surprisingly few studies include age as a prognostic parameter. Only Bisset and Fitzpatrick ${ }^{7}$ found that age significantly predicted DSS using a dichotomy (younger age vs. $>60$ years).

Stage provides prognostically separate groups with respect to survival, DSS, and tumor control, with a distinct dichotomy between Stages I-II and Stages III-IV. T status alone also predicts all three examined outcomes, although not at the 0.01 level for tumor recurrence. $\mathrm{N}$ status, defined in the same dichotomous manner used in the current report, was described as prognostic for survival, ${ }^{6,15}$ for DSS, and for tumor control in terms of recurrence free survival. ${ }^{7}$

In our series, it is noteworthy that three of the four patients who presented with M1 status were in the positive lymph node group. Because both factors are signs of disseminated disease, such a finding is not a surprise. However, keeping the univariate character of the analysis in mind, it is important to realize that the effect of $\mathrm{N}$ status is explained in part by the effect of $\mathrm{M}$ status (confounding), because $\mathrm{M}$ status itself was associated with poor survival and poor DSS in our patients.

Much emphasis has been put on the factors of local extension or extraglandular soft tissue extension (the a-b distinction in the UICC/American Joint Committee Against Cancer [AJCC] T classification) in predicting survival. ${ }^{6,7}$ In our series, this tumor characteristic was not found to separate prognostically different groups. Skin invasion, although it is an element of local extension, was associated with a worse survival rate in our series.

Histologic extraglandular extension or soft tissue invasion has been identified previously as prognostic for survival, ${ }^{6}$ and we can confirm this. We found that perineural growth was prognostic for all three examined outcomes. This feature also was examined but not identified as prognostic for survival by others. ${ }^{6}$

We must not be misled by the significant difference in survival between the three treatment categories examined, because inspection of the figure points out that the significant difference is between patients who underwent surgery or surgery and postoperative radiotherapy on one hand and patients who underwent only radiotherapy on the other. At our institute, the latter patients are selected for this treatment because of their poor chances of surviving surgery or because of unresectable disease. Moreover, a pairwise comparison of survival of patients treated with surgery versus patients treated with surgery and postoperative radiotherapy did not show a significant dif- 
ference $(P=0.50)$. Fitzpatrick and Black, ${ }^{20}$ looking at all salivary gland tumors, found a similar picture: $\mathrm{Pa}$ tients who were treated with surgery with or without postoperative radiation had the same survival rate, whereas patients with a poor prognosis who received radiotherapy obviously did very poorly. Bisset and Fitzpatrick $^{7}$ found the same results for survival but found a significant improvement in locoregional control when radiotherapy was added to a surgical treatment. Weber et al. ${ }^{6}$ examined this effect of added radiotherapy on locoregional control in patients with histopathologic soft tissue disease and also found a significant improvement in locoregional control.

It is always risky to try to draw conclusions about the value of therapy from a retrospective study; however, unfortunately, no prospective randomized trial determining the role of postoperative radiotherapy has been performed to date. In our view, due to the rarity of the disease, such a study will continue to be an unrealistic option in the future, and, even in a multicenter setting, such a study will be unacceptable ethically. Our approach is to combine a functional type of surgery (supraomohyoid neck dissection in the absence of invasion of bone or floor of mouth) with a radiotherapeutic scheme, as described above, except in cases in which there is a total absence of the abovedescribed adverse prognostic factors. Relative support for this combined therapeutic approach is found in the lack of statistically significant differences in survival, DSS, and tumor control in our series: our patients who were determined clinically to have submandibular gland carcinoma with a worse prognosis were selected for postoperative radiotherapy and did as well as the patients who underwent surgery alone, the latter being selected for this treatment type because they were considered to have a carcinoma with a better prognosis. Support also comes from other authors $^{6,7}$ who have found a difference in locoregional control, which is all the more convincing given the negative selection bias for combined treatment. Thus, we also recommend that radiotherapy be added to the treatment of all patients with submandibular gland carcinomas unless they are Stage I-II tumors without association of the above-identified prognostic factors. The same approach also is promoted by Spiro $^{23}$ on the basis of one of the best studies in this regard: the matched-pair analysis of Armstrong et al., ${ }^{26}$ which examined parotid and submandibular carcinomas and found a significant difference in DSS and local control between patients with AJCC Stages III and IV and patients with lymph node disease. Other authors who have analyzed retrospectively the results in their patients with submandibular and parotid carcinomas make similar recommendations. ${ }^{17,25}$
In conclusion, this series provides a number of identified and confirmed prognostic factors for three key outcomes in oncologic treatment analysis. A problem inherently linked to the study subject is the relatively small patient number; nevertheless, our series was marked by a stable treatment protocol and a consequent long term follow-up. Treatment results are comparable to reported results in the literature. Identification of prognostic factors in univariate analysis, however, is no guarantee that these factors will remain independent in multivariate analysis. On the contrary, many of the identified factors in the field of salivary gland malignancies refer to another aspect of the same pathophysiologic mechanism. Logical interrelations are those between $\mathrm{T}, \mathrm{N}$, and $\mathrm{M}$ status; $\mathrm{T}$ status and skin invasion; clinical local extension and histologic soft tissue extension; clinically high grade malignant histology; and perineural, vascular, and extraglandular invasion. Strongly interrelated factors like these are likely to lose part of their prognostic effect when subjected to multivariate analysis; consequently, this approach to analysis can provide more insight into the complex correlations between univariately important prognosticators.

The therapeutic implications of the findings in this study can be summarized in our current treatment policy: Isolated surgical removal can suffice for patients diagnosed with Stage I or II tumors that show no clinical or histologic extraglandular extension and no perineural growth. Radiotherapy should be added in any situation in which the described adverse prognostic factors are present, with high stage, clinical or histologic extraglandular extension, and perineural invasion being the main indicators that a patient will require combination treatment.

\section{REFERENCES}

1. Seifert G, Sobin LH. The World Health Organization's histological classification of salivary gland tumors. A commentary on the second edition. Cancer 1992;70:379-85.

2. Seifert G, Brocheriou C, Cardesa A, Eveson JW. WHO international histological classification of tumours. Tentative histological classification of salivary gland tumours. Pathol Res Pract 1990;186:555-81.

3. Coebergh JWW, van der Heijden LH, Janssen-Heijnen MLG. Cancer of the salivary gland. Coebergh JWW, van der Heijden LH, Janssen-Heijnen MLG, editors. Cancer incidence in the southeast of the Netherlands 1955-1994, a report from the Eindhoven cancer registry, 1995 edition. Eindhoven: Comprehensive Cancer Center South, 1995:24.

4. Eneroth CM. Incidence and prognosis of salivary-gland tumours at different sites. A study of parotid, submandibular and palatal tumours in 2632 patients. Acta Otolaryngol 1970; 263:174-8.

5. Conley CJ, Meyers E, Cole R. Analysis of 115 patients with tumors of the submandibular gland. Ann Otorhinolaryngol 1972;81:323-30. 
6. Weber RS, Byers RM, Petit B, Wolf P, Ang K, Luna M. Submandibular gland tumors. Adverse histologic factors and therapeutic implications. Arch Otolaryngol Head Neck Surg 1990;116:1055-60.

7. Bissett RJ, Fitzpatrick PJ. Malignant submandibular gland tumors. A review of 91 patients. Am J Clin Oncol (CCT) 1988;11:46-51.

8. International Union Against Cancer. UICC TNM atlas: illustrated guide to the TNM/pTNM classification of malignant tumours. 3rd ed, 2nd revision. Berlin: Springer-Verlag, 1992; $50-55$.

9. American Joint Committee on Cancer. Manual for staging of cancer. 4th ed. Philadelphia: J.B. Lippincott, 1992;49-52.

10. Million RR, Cassisi NJ, Mancuso AA. Major salivary gland tumors. Million RR, Cassisi NJ, editors. Management of head and neck cancer: a multidisciplinary approach. 2nd ed. Philadelphia: J.B. Lippincott, 1994;711-35.

11. Spiro RH, Armstrong JA, Harrison L, Geller NL, Shiow-Yun L. Carcinoma of major salivary glands. recent trends. Arch Otolaryngol Head Neck Surg 1989;115:316-21.

12. Spiro RH. Prognostic variables. Johnson JT, Didolkar MS, editors. Head and neck cancer, vol III. Proceedings of the Third International Conference on Head and Neck Cancer. Excerpta Medica. Amsterdam: Elsevier Science Publishers, 1993:619-25.

13. Kaplan EL, Meier P. Nonparametric estimation from incomplete observations. J Am Stat Assoc 1958;53:457-81.

14. Vander Poorten VLM, Balm AJM, Hilgers FJM, Tan IB, LoftusColl BM, Keus RB, et al. The development of a prognostic score for patients with parotid carcinoma. Cancer (in press).

15. Spiro RH, Hadju SI, Strong EW. Tumors of the submaxillary gland. Am J Surg 1976;132:463-8.

16. Batsakis JG. Carcinomas of the submandibular and sublingual glands. Ann Otorhinolaryngol 1986;95:211-2.
17. Borthne A, Kjellevold K, Kaalhus O, Vermund H. Salivary gland malignant neoplasms: treatment and prognosis. Int $\mathrm{J}$ Radiat Oncol Biol Phys 1986;12:747-54.

18. Andersen LJ, Therkildsen MH, Ockelmann HH, Daugard Bentzen J, Schiodt T. Malignant epithelial tumors in the minor salivary glands, the submandibular gland, and the sublingual gland. Prognostic factors and treatment results. Cancer 1991;68:2431-7.

19. Friedman M, Levin B, Grybauskas V, Strorigl T, Manaligod J, Hill JH, et al. Malignant tumors of the major salivary glands. Otolaryngol Clin North Am 1986;19:625-35.

20. Fitzpatrick PJ, Black KM. Salivary gland tumors. J Otolaryngol 1985;14:296-300.

21. Spiro RH. Salivary neoplasms: overview of a 35-year experience with 2,807 patients. Head Neck 1986;8:177-84.

22. Levitt SH, McHugh RB, Gomez-Marin O, Hyams VJ, Soule EH, Strong EW, et al. Clinical staging system for cancer of the salivary gland: a retrospective review. Cancer 1981;47: 2712-24.

23. Spiro RH. Changing trends in the management of salivary tumors. Semin Surg Oncol 1995;11:240-5.

24. O‘Brien CJ, Soong SJ, Herrera GA, Urist MM, Maddox WA. Malignant salivary tumors-analysis of prognostic factors and survival. Head Neck 1986;9:82-92.

25. North CA, Lee D, Piantadosi S, Zahurak M, Johns ME. Carcinoma of the major salivary glands treated by surgery or surgery plus postoperative radiotherapy. Int J Radiat Oncol Biol Phys 1990;18:1319-26.

26. Armstrong JG, Harrison LB, Spiro RH, Fass DE, Strong EW, Fuks ZY. Malignant tumors of major salivary gland origin-a matched pair analysis of the role of combined surgery and postoperative radiotherapy. Arch Otolaryngol Head Neck Surg 1990;116:290-3. 